Gut and Liver, Vol. 9, No. 4, July 2015, pp. 470-477

\title{
Endoscopic and Oncologic Outcomes of Endoscopic Resection for Superficial Esophageal Neoplasm
}

Do Hoon Kim*, Hwoon-Yong Jung*, Eun Jeong Gong*, Ji Young Choi*, Ji Yong Ahn*, Mi Young Kim*, Kwi-Sook Choi*, Jeong Hoon Lee*, Kee Don Choi*, Ho June Song*, Gin Hyug Lee*, Jin Ho Kim*, Young Soo Park ${ }^{\dagger}$, and Seunghee Baek ${ }^{\star}$

Departments of ${ }^{*}$ Gastroenterology, ${ }^{\dagger}$ Pathology, and ${ }^{\ddagger}$ Clinical Epidemiology and Biostatistics, Asan Medical Center, University of Ulsan College of Medicine, Seoul, Korea

Background/Aims: Endoscopic resection (ER) of superficial esophageal neoplasm (SEN) is a technically difficult procedure. We investigated the clinical outcomes of ER for SEN to determine its feasibility and effectiveness. Methods: Subjects who underwent ER for SEN at Asan Medical Center between December 1996 and December 2010 were eligible. The clinical features of patients and tumors, histopathological characteristics, adverse events, ER results and survival were investigated. Results: A total of 129 patients underwent ER for 147 SENs. En bloc resection (EnR) was performed in 118 lesions (80.3\%). Complete resection (CR) was accomplished in 128 lesions (86.5\%), and curative resection (CuR) was performed in 118 lesions (79.7\%). The EnR, CR, and CuR rates were significantly greater in the endoscopic submucosal dissection group when compared to those in the endoscopic resection group. Adverse events occurred in 22 patients (17.1\%), including bleeding $(n=2,1.6 \%)$, perforation $(n=12,9.3 \%)$, and stricture $(n=8,6.2 \%)$. Local tumor recurrence occurred in $2.0 \%$ of patients during a median follow-up of 34.8 months. The 5-year overall and disease-specific survival rates were $94.0 \%$ and $97.5 \%$, respectively. Conclusions: ER is a feasible and effective method for the treatment of SEN as indicated by favorable clinical outcomes. (Gut Liver 2015;9:470-477)

Key Words: Esophageal neoplasms; Treatment outcome; Endoscopic resection

\section{INTRODUCTION}

Esophageal cancer is the eighth most common cancer worldwide. ${ }^{1,2}$ In Korea, the detection rate of early-stage squamous cell carcinoma (SCC) has increased with the widespread endoscopic screening of asymptomatic individuals and increased endoscopist's experience and awareness. ${ }^{2-5}$ In the past, esophagectomy with lymph node dissection was the treatment of choice for SCC and was often performed even in patients with esophageal highgrade dysplasia (HGD).$^{6-8}$ However, surgical resection is associated with significant mortality and morbidity regardless of the experience of the surgeon. ${ }^{9}$ Consequently, endoscopic treatment of superficial esophageal neoplasm (SEN), including early-stage SCC and HGD, has attracted interest as an alternative therapy.

Endoscopic resection (ER), including endoscopic mucosal resection (EMR) and endoscopic submucosal dissection (ESD), is regarded as an effective, minimally invasive treatment for SEN, and has been performed in many centers in several countries. ${ }^{10-17}$ Studies have shown that in almost 50\% of patients treated by EMR, the procedure is performed by piecemeal resection, particularly when the lesion is $>20 \mathrm{~mm} \cdot{ }^{11,13,15-18}$ Therefore, EMR has been associated with high local recurrence rates of $24 \%$ to $26 \% .^{1{ }^{1,19-21}}$ ESD enables en bloc resection (EnR) of tumors regardless of size; however, it is a technically difficult and time-consuming procedure that is associated with an increased risk of complications. In the present study, we investigated the clinical outcomes of ER in patients with SEN.

\section{MATERIALS AND METHODS}

\section{Patients}

Patients who underwent ER for SEN at Asan Medical Center between December 1996 and December 2010 were eligible. SEN included SCC confined to the mucosal layer and HGD, and patients who were previously diagnosed with esophageal neoplasm were excluded. Preprocedural diagnosis was made by

\footnotetext{
Correspondence to: Hwoon-Yong Jung

Department of Gastroenterology, Asan Medical Center, University of Ulsan College of Medicine, 88 Olympic-ro 43-gil, Songpa-gu, Seoul 138-736, Korea

Tel: +82-2-3010-3197, Fax: +82-2-476-0824, E-mail: hwoonymd@gmail.com

Received on July 16, 2013. Revised on December 26, 2013. Accepted on May 5, 2014. Published online December 5, 2014 pISSN 1976-2283 eISSN 2005-1212 http://dx.doi.org/10.5009/gnl13263

@ This is an Open Access article distributed under the terms of the Creative Commons Attribution Non-Commercial License (http://creativecommons.org/licenses/by-nc/4.0) which permits unrestricted non-commercial use, distribution, and reproduction in any medium, provided the original work is properly cited.
} 
white-light endoscopy and narrow band imaging and by Lugol chromoendoscopy (LCE). Endoscopic ultrasound was performed to evaluate the exact depth of invasion in patients with SCC. Computed tomography (CT) scans of the chest and upper abdomen and positron emission tomography (PET)-CT scans were performed in all patients with SEN to identify possible distant metastasis or lymph node metastases.

Clinical characteristics, including patient-, tumor- (the location and size of lesions, and histologic diagnosis), and procedure-related (procedure time and adverse events) factors were collected from medical records. In addition, the clinical outcomes of ER, including complete resection (CR) and curative resection $(\mathrm{CuR})$ rates, local recurrence rates, the development of synchronous or metachronous lesions, and the overall and disease-specific survivals were investigated. Informed consent was obtained from all patients before ER, and the retrospective analysis was approved by the Institutional Review Board of Asan Medical Center (2011-0793).

\section{Endoscopic treatment}

ER was performed by three experienced endoscopists (H.Y.J., H.J.S., and K.D.C.), with patients under conscious sedation or general anesthesia. Resection was performed by EMR before 2004 and ESD after 2005. ER was performed with a forwardviewing endoscope (GIF-H260; Olympus, Tokyo, Japan) and the tip of the endoscope was fitted with a transparent attachment (D-201-11814; Olympus) to obtain a constant endoscopic view and to create tension on the connective tissue during submucosal dissection.

Before ER, endoscopic examination was performed by LCE through the direct instillation of $20 \mathrm{~mL}$ of 3\% Lugol's solution to evaluate the lateral spread of tumors. The marking was performed on the borders of the lesions, and normal saline containing small amounts of 0.005\% epinephrine and indigo carmine was then injected submucosally. A small incision was made with a hook knife (Olympus) followed by a circumferential mucosal incision outside the marking. The submucosal connective tissue just beneath the lesion was dissected from the muscularis propria with an insulated-tip knife (Olympus). Submucosal injection was repeated as needed, and further dissection was performed to ensure a deep resection margin (Fig. 1). Hemostasis was performed during or after the dissection using hemostatic forceps (FD-410LR; Olympus).

EMR was performed using the EMR-L or EMR-C method. EMR-L denotes a suck-and-cut method with a ligation device similar to that used in variceal ligation. The target lesion was sucked into the cylinder and a rubber band was released to create a pseudopolyp. Finally, a snare was placed, and the lesion was excised using a cutting current (Fig. 2). ${ }^{22,23}$ In the EMR-C method, a specifically designed transparent plastic cap was at-
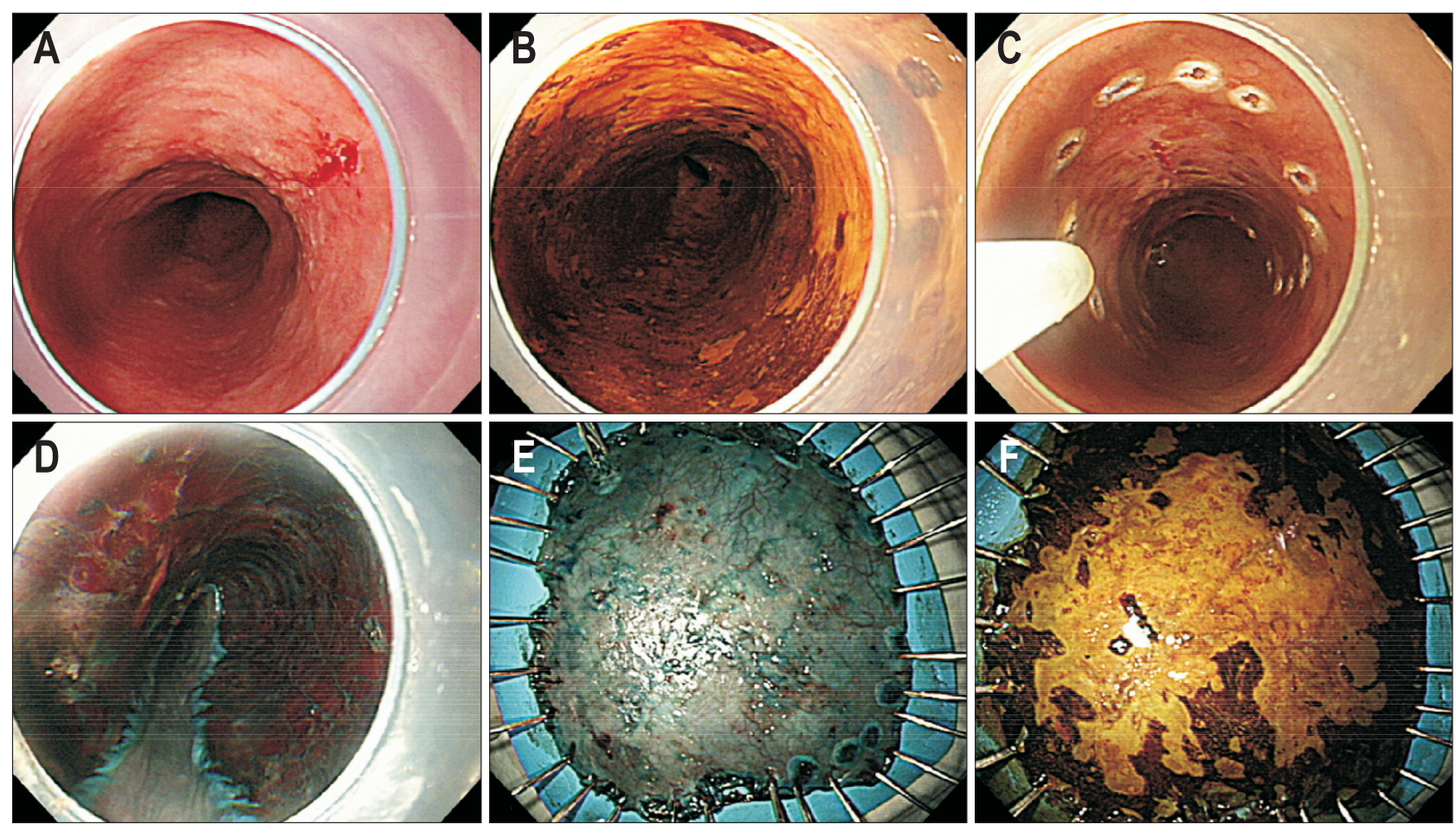

Fig. 1. Endoscopic submucosal dissection of an esophageal neoplasm. (A) A hyperemic, subtly nodular lesion in the midthoracic esophagus on conventional white-light endoscopy. (B) Lugol chromoendoscopy demarcating the lesion. (C) Markings around the lesion. (D) An artificial ulcer after submucosal dissection. (E) En bloc resected specimen examined by conventional white-light endoscopy. (F) Chromoendoscopic findings of a resected specimen revealing a Lugol-void lesion. 

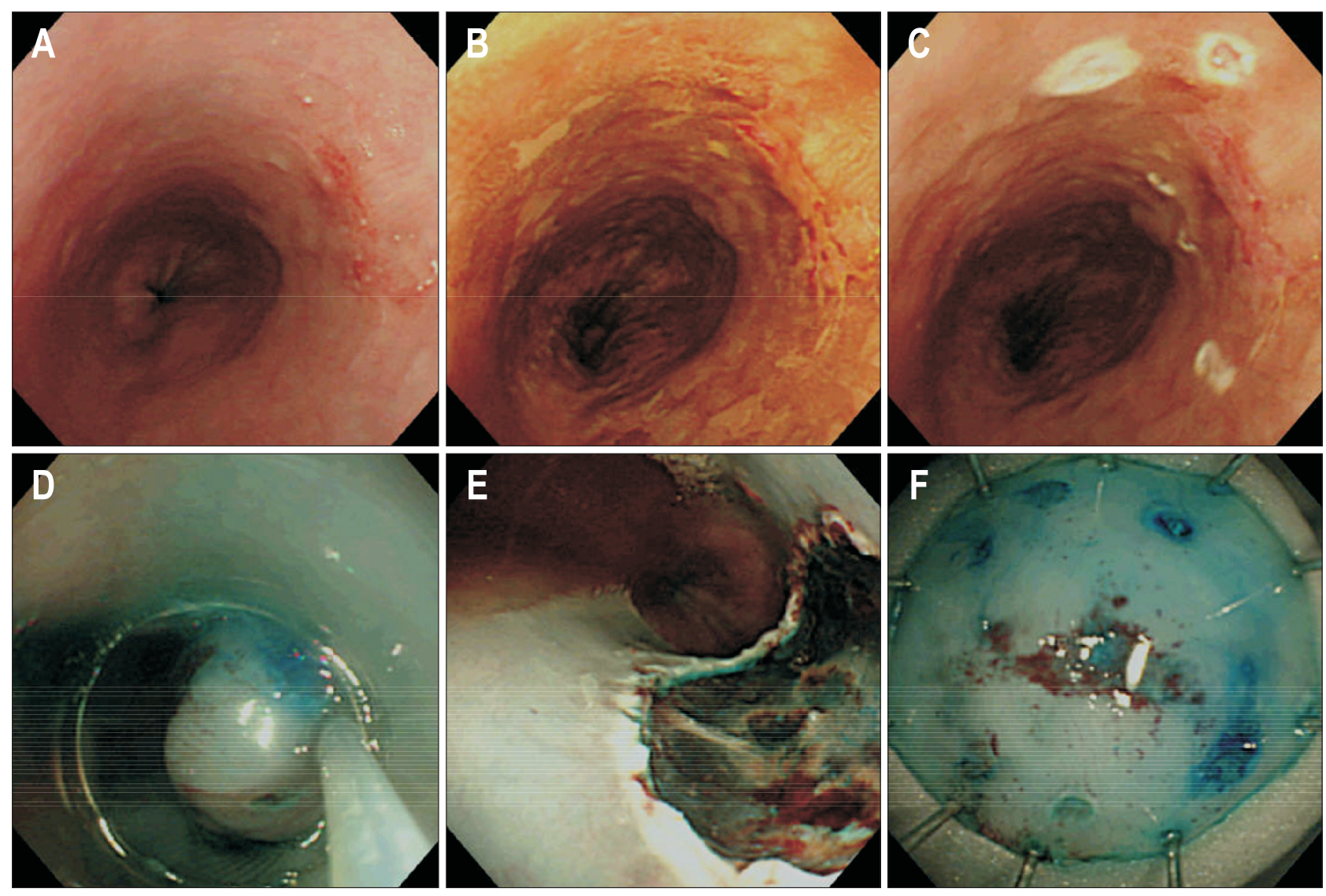

Fig. 2. Endoscopic mucosal resection of an esophageal neoplasm. (A) A hyperemic, coarse lesion in the mid thoracic esophagus on conventional white-light endoscopy. (B) Lugol chromoendoscopy showing the lesion. (C) Markings made around the lesion. (D) Resection performed using a snare after submucosal saline injection. (E) An artificial ulcer after endoscopic resection. (F) En bloc resected specimen.

tached to the end of the endoscope, and the lesion was sucked into the cap and resected with a diathermy loop, which had been loaded onto a specially designed groove on the edge of the cap. $^{24}$

Follow-up endoscopy with LCE was performed every 6 months during the first 2 years after the ER and annually thereafter. Patients found to have SCC were assessed by additional CT scans of the chest and abdomen. PET-CT scans were performed at 1, 3, and 5 years.

\section{Histopathological evaluation}

The resected specimens were fixed in formalin and serially sectioned perpendicularly at $2 \mathrm{~mm}$ intervals. The size of the resected specimens and tumors, depth of invasion, the presence of lymphovascular invasion or perineural invasion, histologic differentiation, and resection margins were evaluated. All sections were subjected to detailed pathological review according to the guidelines of Clinical and Pathological Studies in Carcinoma of the Esophagus. ${ }^{25,26}$ Based on these guidelines, tumors were classified into three categories according to the depth of invasion as follows: $\mathrm{m} 1$, intraepithelial carcinoma; m3, tumor extremely close to or infiltrating the muscularis mucosa; and $\mathrm{m} 2$, tumors located between $\mathrm{m} 1$ and $\mathrm{m} 3$. Sm1 was defined as a submucosally invaded tumor that extended up to $200 \mu \mathrm{m}$ below the lower border of the muscularis mucosa. ${ }^{27}$ T0 was defined as HGD.

\section{Definitions}

EnR was defined as resection of targeted lesions in one piece regardless of the depth of invasion and lymphovascular invasion. CR was defined as tumor-free lateral margins $>2 \mathrm{~mm}$ and tumor-free vertical margins $>0.5 \mathrm{~mm}$ on histologic examination. A multi-fragment section was regarded as CR when all fragments could be evaluated adequately after achieving perfect reconstruction. If the lateral margin of the lesion could not be evaluated histologically because of the effect of the electrosurgical current or mechanical damage, the resection was regarded as incomplete.

CuR was defined as the absence of a poorly differentiated component, lymphovascular invasion or perineural invasion, and submucosal invasion $<200 \mu \mathrm{m}$ from the muscularis mucosa. Non-CuR was defined as tumors that did not fulfill the above criteria for CuR regardless of CR.

Local recurrence was defined as an iodine-unstained area that was detected at the site of resection and confirmed histologically. Synchronous lesions were defined as those detected in a 
Table 1. Patient Characteristics in the Endoscopic Mucosal Resection and Endoscopic Submucosal Dissection Groups

\begin{tabular}{|c|c|c|c|c|}
\hline Characteristic & Total $(n=147)$ & EMR group $(\mathrm{n}=39)$ & ESD group $(n=108)$ & p-value \\
\hline Gender, male:female & $124: 5$ & $30: 0$ & $94: 5$ & \\
\hline Age, yr & $67(45-86)$ & $66(45-84)$ & $67(49-86)$ & 0.415 \\
\hline Smoking & & & & 0.667 \\
\hline Current smoker & $52(40.3)$ & $16(53.3)$ & 36 (36.7) & \\
\hline Ex-smoker & $52(40.3)$ & $9(30)$ & 43 (43.9) & \\
\hline Nonsmoker & $25(19.4)$ & $5(16.7)$ & $20(20.4)$ & \\
\hline Alcohol & & & & 0.542 \\
\hline Alcoholics & $72(55.8)$ & $20(66.7)$ & $52(53.0)$ & \\
\hline Ex-alcoholics & $32(24.8)$ & $4(13.3)$ & $28(28.6)$ & \\
\hline Nonalcoholics & $25(19.4)$ & $6(20.0)$ & 19 (19.4) & \\
\hline Location & & & & 0.290 \\
\hline Upper esophagus & $4(2.7)$ & $2(5.1)$ & $2(1.9)$ & \\
\hline Middle esophagus & $92(62.6)$ & $22(56.4)$ & $70(64.8)$ & \\
\hline Lower esophagus & $51(34.7)$ & 15 (38.5) & 36 (33.3) & \\
\hline Lesion size, $\mathrm{mm}$ & $15(2-60)$ & $11(2-40)$ & $15(2-60)$ & 0.017 \\
\hline Circumference, $\%$ & & & & 0.372 \\
\hline$<50$ & $113(76.9)$ & $32(82.0)$ & $81(75)$ & \\
\hline $50-75$ & 26 (17.7) & $4(10.3)$ & $22(20.4)$ & \\
\hline$>75$ & $8(5.4)$ & $3(7.7)$ & $5(4.6)$ & \\
\hline Histology & & & & 0.640 \\
\hline Dysplasia & $30(20.4)$ & $10(25.6)$ & $20(18.5)$ & \\
\hline Squamous cell carcinoma & 117 (79.6) & $29(74.4)$ & $88(81.5)$ & \\
\hline
\end{tabular}

Data are presented as number (\%) or median (range).

EMR, endoscopic mucosal resection; ESD, endoscopic submucosal dissection.

different location within 1 year of the initial ER, and metachronous lesions were those detected more than 1 year after ER.

Complications included bleeding, perforation, and postoperative stricture. Procedure- related bleeding was defined as (1) bleeding confirmed by routine, second-look endoscopy within 24 hours; (2) clinical evidence of melena or hematemesis; or (3) massive bleeding such as that requiring transfusion or bleeding in which the level of hemoglobin fell $2 \mathrm{~g} / \mathrm{dL}$ after the procedures. Perforation was diagnosed endoscopically during the procedure when the mediastinal connective tissue could be visualized, or radiographically as the presence of free air on chest radiography. Stricture was defined as the inability to pass a standard 11-mm diameter endoscope through the stricture.

\section{Statistical analysis}

Differences among clinical characteristics were determined using Student t-test or chi-square test, as appropriate. When the sample size was small, the Mann-Whitney U-test or Fisher exact test was used. Kaplan-Meier analysis and the log-rank test were used to assess survival. All statistical analyses were performed using SPSS version 17.0 (SPSS Inc., Chicago, IL, USA), and a pvalue $<0.05$ was considered statistically significant.

\section{RESULTS}

\section{Clinicopathologic characteristics}

During the study period, 129 subjects underwent ER for 147 lesions, including 30 HGD and 117 SCC (Table 1). The median age was 67 years (range, 45 to 86 years) and the male-to-female ratio was 24.8:1. The median size of tumors resected by EMR and ESD was $11 \mathrm{~mm}$ (range, 2 to $40 \mathrm{~mm}$ ) and $15 \mathrm{~mm}$ (range, 2 to $60 \mathrm{~mm})$, respectively. Of the 117 SCCs, 104 (88.9\%) were confined to the mucosal layer, and 13 (11.1\%) invaded the submucosal layer. Four lesions (2.7\%) were located in the upper esophagus, 92 (62.6\%) in the middle esophagus, and 51 (34.7\%) in the lower esophagus. Among these, 34 lesions (23.1\%) occupied more than one half of the luminal circumference.

\section{Clinical and oncologic outcomes of ER}

EMR and ESD were performed in 108 (73.5\%) and 39 (26.5\%) lesions, respectively (Table 2). The median size of resected specimens was significantly larger in the ESD group than in the EMR group ( $35 \mathrm{~mm}$ vs $26 \mathrm{~mm}, \mathrm{p}<0.001$ ). The median procedure time was 37 minutes (range, 4 to 120 minutes), and the procedure time was longer in the ESD group. 
Table 2. Comparison between Endoscopic Mucosal Resection and Endoscopic Submucosal Dissection for Superficial Esophageal Neoplasm

\begin{tabular}{|c|c|c|c|c|}
\hline Variable & Total $(n=147)$ & EMR group $(n=39)$ & ESD group $(n=108)$ & p-value \\
\hline Resected specimen size, $\mathrm{mm}$ & $33(5-70)$ & $26(5-65)$ & $35(15-70)$ & $<0.001$ \\
\hline Procedure time, $\min$ & $37(4-120)$ & $21(4-63)$ & $40(13-120)$ & $<0.004$ \\
\hline Depth of invasion & & & & 0.605 \\
\hline T0 & $30(20.4)$ & $10(25.6)$ & $20(18.5)$ & \\
\hline $\mathrm{m} 1$ & $62(42.2)$ & $14(35.9)$ & $48(44.5)$ & \\
\hline $\mathrm{m} 2$ & $31(21.1)$ & 7 (18.0) & $24(22.2)$ & \\
\hline m3 & $11(7.5)$ & $2(5.1)$ & $9(8.3)$ & \\
\hline $\mathrm{sm}$ & $13(8.8)$ & $6(15.4)$ & $7(6.5)$ & \\
\hline En bloc resection & $118(80.3)$ & $20(51.3)$ & $98(90.7)$ & $<0.001$ \\
\hline Complete resection & $128(86.5)$ & $28(71.8)$ & 99 (91.7) & 0.001 \\
\hline Curative resection & 118 (79.7) & $25(64.1)$ & 92 (85.3) & 0.011 \\
\hline \multicolumn{5}{|l|}{ Resection margin of specimen } \\
\hline Positive lateral margin & $17(11.5)$ & $10(25.6)$ & $7(6.4)$ & 0.001 \\
\hline Positive vertical margin & $1(0.7)$ & 0 & $1(0.9)$ & 1.000 \\
\hline Positive lymphovascular invasion & $4(2.7)$ & 0 & $4(3.6)$ & 0.573 \\
\hline Complication & $22(17.1)$ & $3(10.0)$ & $18(18.2)$ & 0.282 \\
\hline Bleeding & $2(1.6)$ & 0 & $2(2.0)$ & 1.000 \\
\hline Perforation & $12(9.3)$ & 0 & $12(12.1)$ & 0.066 \\
\hline Stricture & $8(6.2)$ & $3(10.0)$ & $5(5.1)$ & 0.424 \\
\hline
\end{tabular}

Data are presented as number (\%) or median (range).

EMR, endoscopic mucosal resection; ESD, endoscopic submucosal dissection.

Table 3. Demographic Features of Patients Having Recurrence after Curative Resection

\begin{tabular}{|c|c|c|c|c|c|c|c|c|}
\hline Patient & ER method & $\begin{array}{l}\text { Depth of } \\
\text { invasion }\end{array}$ & $\begin{array}{l}\text { Lesion size, } \\
\mathrm{mm}\end{array}$ & $\begin{array}{l}\text { No. of } \\
\text { resection }\end{array}$ & $\begin{array}{l}\text { Type of } \\
\text { recurrence }\end{array}$ & $\begin{array}{l}\text { Duration, } \\
\text { mo }\end{array}$ & $\begin{array}{l}\text { Depth of } \\
\text { recurrence }\end{array}$ & $\begin{array}{c}\text { Additional } \\
\text { treatment }\end{array}$ \\
\hline 1 & EMR & T0 & 16 & PR & Synch & 9 & $\mathrm{~m} 2$ & $\mathrm{OP}$ \\
\hline 2 & EMR & $\mathrm{m} 1$ & 40 & PR & Synch & 10.2 & T0 & EMR \\
\hline 3 & ESD & $\mathrm{m} 1$ & 15 & ER & Synch & 7.7 & $\mathrm{~m} 1$ & ESD \\
\hline 4 & ESD & $\mathrm{m} 1$ & 27 & ER & Synch & 3 & T0 & EMR \\
\hline 5 & ESD & $\mathrm{m} 2$ & 10 & ER & Synch & 7.2 & $\mathrm{pm}$ & $\mathrm{OP}$ \\
\hline 6 & EMR & $\mathrm{m} 2$ & 22 & PR & Metach & 89.5 & - & CTx \\
\hline 7 & ESD & $\mathrm{m} 1$ & 27 & PR & Metach & 18.7 & $\mathrm{~m} 1$ & ESD \\
\hline 8 & ESD & $\mathrm{m} 1$ & 13 & ER & Metach & 13.2 & $\mathrm{~m} 1$ & ESD \\
\hline 9 & ESD & $\mathrm{m} 2$ & 29 & ER & Metach & 19.1 & T0 & ESD \\
\hline
\end{tabular}

ER, en bloc resection; EMR, endoscopic mucosal resection; PR, piecemeal resection; Synch, synchronous lesion; OP, operation; ESD, endoscopic submucosal dissection; Metach, metachronous lesion; CTx, chemotherapy.

EnR was achieved in 118 of 147 lesions (80.3\%), with CR achieved in 128 lesions (86.5\%) and CuR in 118 lesions (79.7\%). EnR, CR, and CuR rates were higher in the ESD group than in the EMR group. Of the 118 lesions with CuR, recurrence occurred in nine patients, including five synchronous lesions and four metachronous lesions, at a median follow-up of 34.8 months (range, 8 to 138 months) (Table 3). The median duration from ER to recurrence was 10.2 months (range, 3 to 89.5 months), and ER for synchronous or metachronous lesions was feasible in six of nine patients (66.7\%). None of the patients showed local recurrence.

Among 30 patients with non-CuR, 10 showed invasion of the submucosal layer, 18 had a positive resection margin, and four had lymphovascular invasion. Of these, local recurrence occurred in three patients. Nodal or distant metastasis was not observed in any of these patients during the follow-up period.

Adverse events occurred in 22 patients (17.1\%) and included bleeding $(n=2,1.6 \%)$, perforation $(n=12,9.3 \%)$, and stricture $(n=8,6.2 \%)$. All patients with delayed bleeding were treated endoscopically. Perforation accompanied by mediastinal emphy- 

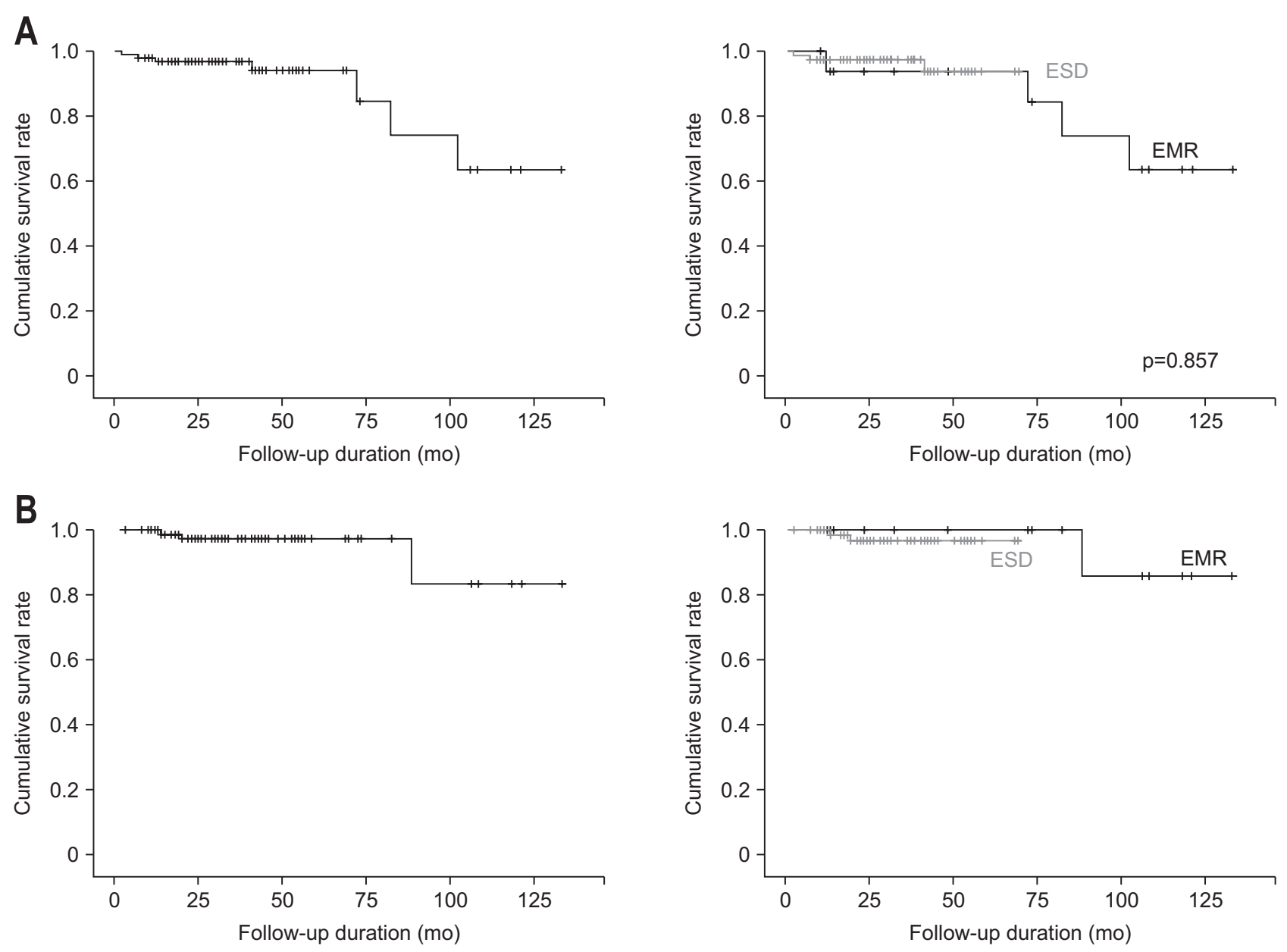

Fig. 3. Kaplan-Meier analysis. (A) Overall cumulative survival rates after curative resection. (B) Overall cumulative disease-free survival rates after curative resection.

ESD, endoscopic submucosal dissection; EMR, endoscopic mucosal resection.

sema was detected in 12 patients, and all cases occurred in the ESD group. Five patients were diagnosed endoscopically during the procedure, and seven patients were diagnosed by chest radiography performed after the procedure. All patients with perforation recovered uneventfully without any additional intervention. Among the patients with stricture, four complained of dysphagia and were managed with an average of 5.5 sessions of endoscopic balloon dilatation.

During the follow-up period, seven patients had died; one died of esophageal cancer-related causes, and six died of unrelated causes. The 5-year overall and disease-specific survival rates were 94.0\% and 97.5\%, respectively (Fig. 3).

\section{DISCUSSION}

In the present study, we investigated the clinical outcomes of ER in 147 SENs. The overall EnR, CR, and CuR rates were 80.3\%, 86.5\%, and 79.7\%, respectively. EnR, CR, and CuR rates were significantly higher in the ESD group than those in the EMR group. Adverse events occurred in 21 patients, including bleeding (1.6\%), perforation (9.3\%), and stricture (6.2\%). The local tumor recurrence rate was $2.0 \%$ during a median follow-up period of 34.8 months. The 5-year overall and disease-specific survival rates were $94.0 \%$ and $97.5 \%$, respectively. To the best of our knowledge, this is the first study to evaluate the clinical outcomes of ER in a large number of SENs with long-term follow-up data.

ER is accepted as the standard treatment for gastric neoplasm, and its feasibility and effectiveness have been demonstrated in recent studies. ${ }^{28,29}$ Although ER has been performed in patients with SEN, few studies have assessed its feasibility and effectiveness for the treatment of SENs, and the long-term clinical outcomes remain uncertain. ${ }^{16,18,21,30}$ In the present study, we evaluated the outcomes of ER, including EnR, CR, and $\mathrm{CuR}$, and showed that ER is an effective method for the treatment of SENs with acceptable adverse events. In addition, we showed that despite a longer procedure time associated with the ESD procedure, ESD showed advantages over EMR by enabling EnR of larger lesions. Regarding the incidence of complications, more adverse events occurred in the ESD group; however, all patients 
recovered uneventfully, and there was no statistically significant difference between the ESD and EMR groups.

In the postoperative management of patients with SEN, esophageal stricture is an important problem because it is associated with impaired quality of life. The possibility of stricture increases when the circumference of the lesion exceeds threefourths of the total circumference of the esophagus. ${ }^{16,31,32}$ In addition, longitudinal mucosal defects longer than $30 \mathrm{~mm}$ have been reported as a significant risk factor for the development of esophageal stricture. ${ }^{33}$ In the present study, the incidence of stricture was $6.2 \%$, which is lower than that reported previously. ${ }^{34,35}$ Esophageal stricture occurred in three cases in the EMR group and five cases in the ESD group. The average diameter of resected specimens was $54.6 \mathrm{~mm}$ in the ESD group and $26.0 \mathrm{~mm}$ in the EMR group; however, the difference did not reach statistical significance.

Assessment of long-term outcomes showed 5-year overall and disease-specific survival rates of $94.0 \%$ and $97.5 \%$, respectively. During a median follow-up period of 34.8 months, the overall recurrence rate was $11.6 \%$ (six synchronous, eight metachronous, and three local recurrence), and most recurrences occurred within 2 years of the initial ER. Therefore, endoscopic surveillance for the first 2 years after ER is essential for the early detection of recurrence. In the present study, of 17 cases of recurrence, $11(64.7 \%)$ were treated with repeated ER and remained disease-free.

According to the guidelines of the Japanese Esophageal Society for the diagnosis and treatment of esophageal SCC, ER is recommended in patients with SEN limited to high-grade intraepithelial neoplasia, including $\mathrm{m} 1$ and $\mathrm{m} 2$ without vascular invasion or lymph node metastasis. ${ }^{36}$ Tumors invading the muscularis mucosa $(\mathrm{m} 3)$ or submucosa $(\mathrm{sm} 1)$ are associated with a higher risk of lymph node metastasis and ER should be considered when no further risk factors such as a poorly differentiated component or lymphovascular invasion are present. ${ }^{37,38}$ However, even in cases of invasion into the muscularis mucosa, if the lower lamina muscularis mucosae (LMM) invasion width is $\leq 3.0 \mathrm{~mm}$ and there is no evidence of lymphovascular invasion, the patient can be carefully observed without additional treatment. ${ }^{39}$ In addition, in tumors with minute submucosal invasion, the choice of ER or surgical resection should be made after balancing the risk of recurrence against the operative risk, especially in elderly patients with comorbidities. In the present study, all 11 cases with $\mathrm{m} 3$ showed CR without recurrence during the follow-up period. Two of 10 cases with submucosal invasion were observed without additional intervention because of the patients' refusal. At the time of the study, these patients were alive without recurrence, and the lower LMM invasion width was 0.4 and $2.4 \mathrm{~mm}$, respectively.

This study had several limitations. First, it was a retrospective study conducted in a single center, which could have led to selection bias in the decision to undergo ER versus surgical treat- ment. Secondly, as EMR was performed before 2004 and ESD has been performed since 2005 , the median follow-up period of the ESD group was relatively shorter than that of the EMR group.

In conclusion, ER for SENs is a feasible and effective procedure, as indicated by favorable clinical outcomes. Although ESD is technically difficult and more time-consuming than EMR, ESD has advantages regarding EnR, CR, and CuR, which may lead to longer-term recurrence-free survival.

\section{CONFLICTS OF INTEREST}

The authors have no financial interest or affiliation with any commercial supporter or providers of any commercial services. The authors are solely responsible for the content and writing of this paper.

\section{REFERENCES}

1. Jemal A, Siegel R, Ward E, et al. Cancer statistics, 2008. CA Cancer J Clin 2008;58:71-96.

2. National Cancer Information Center [Internet]. Goyang: National Cancer Center; c2012 [cited 2013 Jul 19]. Available from: http:// www.cancer.go.kr.

3. Kumagai Y, Monma K, Kawada K. Magnifying chromoendoscopy of the esophagus: in-vivo pathological diagnosis using an endocytoscopy system. Endoscopy 2004;36:590-594.

4. Yoshida T, Inoue H, Usui S, Satodate H, Fukami N, Kudo SE. Narrow-band imaging system with magnifying endoscopy for superficial esophageal lesions. Gastrointest Endosc 2004;59:288-295.

5. Kodashima S, Fujishiro M, Takubo K, et al. Ex-vivo study of highmagnification chromoendoscopy in the gastrointestinal tract to determine the optimal staining conditions for endocytoscopy. Endoscopy 2006;38:1115-1121.

6. Kato H, Tachimori Y, Watanabe H, Yamaguchi H, Ishikawa T, Itabashi M. Superficial esophageal carcinoma: surgical treatment and the results. Cancer 1990;66:2319-2323.

7. Kato H, Tachimori Y, Mizobuchi S, Igaki H, Ochiai A. Cervical, mediastinal, and abdominal lymph node dissection (three-field dissection) for superficial carcinoma of the thoracic esophagus. Cancer 1993;72:2879-2882.

8. Roth JA, Putnam JB Jr. Surgery for cancer of the esophagus. Semin Oncol 1994;21:453-461.

9. Birkmeyer JD, Stukel TA, Siewers AE, Goodney PP, Wennberg DE, Lucas FL. Surgeon volume and operative mortality in the United States. N Engl J Med 2003;349:2117-2127.

10. May A, Ell C. Diagnosis and treatment of early esophageal cancer. Curr Opin Gastroenterol 2006;22:433-436.

11. Pech 0, May A, Gossner L, et al. Curative endoscopic therapy in patients with early esophageal squamous-cell carcinoma or highgrade intraepithelial neoplasia. Endoscopy 2007;39:30-35.

12. Ell C, May A, Pech 0, et al. Curative endoscopic resection of early 
esophageal adenocarcinomas (Barrett's cancer). Gastrointest Endosc 2007;65:3-10.

13. Ciocirlan M, Lapalus MG, Hervieu V, et al. Endoscopic mucosal resection for squamous premalignant and early malignant lesions of the esophagus. Endoscopy 2007;39:24-29.

14. Pech 0, Gossner L, May A, Vieth M, Stolte M, Ell C. Endoscopic resection of superficial esophageal squamous-cell carcinomas: Western experience. Am J Gastroenterol 2004;99:1226-1232.

15. Higuchi K, Tanabe S, Koizumi W, et al. Expansion of the indications for endoscopic mucosal resection in patients with superficial esophageal carcinoma. Endoscopy 2007;39:36-40.

16. Oyama T, Tomori A, Hotta K, et al. Endoscopic submucosal dissection of early esophageal cancer. Clin Gastroenterol Hepatol 2005;3(7 Suppl 1):S67-S70.

17. Ono H, Kondo H, Gotoda T, et al. Endoscopic mucosal resection for treatment of early gastric cancer. Gut 2001;48:225-229.

18. Ishihara R, Iishi H, Uedo $\mathrm{N}$, et al. Comparison of EMR and endoscopic submucosal dissection for en bloc resection of early esophageal cancers in Japan. Gastrointest Endosc 2008;68:1066-1072.

19. Katada C, Muto M, Manabe T, Ohtsu A, Yoshida S. Local recurrence of squamous-cell carcinoma of the esophagus after EMR. Gastrointest Endosc 2005;61:219-225.

20. Esaki M, Matsumoto T, Hirakawa K, et al. Risk factors for local recurrence of superficial esophageal cancer after treatment by endoscopic mucosal resection. Endoscopy 2007;39:41-45.

21. Ishihara $\mathrm{R}$, Iishi $\mathrm{H}$, Takeuchi $\mathrm{Y}$, et al. Local recurrence of large squamous-cell carcinoma of the esophagus after endoscopic resection. Gastrointest Endosc 2008;67:799-804.

22. Ell C, May A, Gossner L, et al. Endoscopic mucosal resection of early cancer and high-grade dysplasia in Barrett's esophagus. Gastroenterology 2000;118:670-677.

23. May A, Gossner L, Behrens A, et al. A prospective randomized trial of two different endoscopic resection techniques for early stage cancer of the esophagus. Gastrointest Endosc 2003;58:167-175.

24. Inoue H, Endo M, Takeshita K, Yoshino K, Muraoka Y, Yoneshima H. A new simplified technique of endoscopic esophageal mucosal resection using a cap-fitted panendoscope (EMRC). Surg Endosc 1992;6:264-265.

25. Kodama M, Kakegawa T. Treatment of superficial cancer of the esophagus: a summary of responses to a questionnaire on superficial cancer of the esophagus in Japan. Surgery 1998;123:432-439.

26. Japan Esophageal Society. Japanese classification of esophageal cancer, tenth edition: part I. Esophagus 2009;6:1-25.

27. Chiba T, Kawachi H, Kawano T, et al. Independent histological risk factors for lymph node metastasis of superficial esophageal squamous cell carcinoma: implication of claudin-5 immunohisto- chemistry for expanding the indications of endoscopic resection. Dis Esophagus 2010;23:398-407.

28. Kuwano H, Nishimura Y, Ohtsu A, et al. Guidelines for diagnosis and treatment of carcinoma of the esophagus April 2007 edition: part I edited by the Japan Esophageal Society. Esophagus 2008;5:61-73.

29. Tajima Y, Nakanishi Y, Ochiai A, et al. Histopathologic findings predicting lymph node metastasis and prognosis of patients with superficial esophageal carcinoma: analysis of 240 surgically resected tumors. Cancer 2000;88:1285-1293.

30. Fujishiro M, Yahagi N, Kakushima N, et al. Endoscopic submucosal dissection of esophageal squamous cell neoplasms. Clin Gastroenterol Hepatol 2006;4:688-694.

31. Watanabe K, Ogata S, Kawazoe S, et al. Clinical outcomes of EMR for gastric tumors: historical pilot evaluation between endoscopic submucosal dissection and conventional mucosal resection. Gastrointest Endosc 2006;63:776-782.

32. Ono S, Fujishiro M, Niimi K, et al. Long-term outcomes of endoscopic submucosal dissection for superficial esophageal squamous cell neoplasms. Gastrointest Endosc 2009;70:860-866.

33. Takahashi H, Arimura Y, Masao H, et al. Endoscopic submucosal dissection is superior to conventional endoscopic resection as a curative treatment for early squamous cell carcinoma of the esophagus (with video). Gastrointest Endosc 2010;72:255-264.e2.

34. Eguchi T, Nakanishi Y, Shimoda T, et al. Histopathological criteria for additional treatment after endoscopic mucosal resection for esophageal cancer: analysis of 464 surgically resected cases. Mod Pathol 2006;19:475-480.

35. Oka S, Tanaka S, Kaneko I, et al. Advantage of endoscopic submucosal dissection compared with EMR for early gastric cancer. Gastrointest Endosc 2006;64:877-883.

36. Ono S, Fujishiro M, Niimi K, et al. Predictors of postoperative stricture after esophageal endoscopic submucosal dissection for superficial squamous cell neoplasms. Endoscopy 2009;41:661665.

37. Mizuta H, Nishimori I, Kuratani Y, Higashidani Y, Kohsaki T, Onishi S. Predictive factors for esophageal stenosis after endoscopic submucosal dissection for superficial esophageal cancer. Dis Esophagus 2009;22:626-631.

38. Ezoe Y, Muto M, Horimatsu T, et al. Efficacy of preventive endoscopic balloon dilation for esophageal stricture after endoscopic resection. J Clin Gastroenterol 2011;45:222-227.

39. Choi JY, Park YS, Jung HY, et al. Feasibility of endoscopic resection in superficial esophageal squamous carcinoma. Gastrointest Endosc 2011;73:881-889.e2. 